ARTICLE

DOI: $10.1038 / s 41467-017-00915-8$

\title{
Selective binding of choline by a phosphate- coordination-based triple helicate featuring an aromatic box
}

Chuandong Jia ${ }^{1}$, Wei Zuo ${ }^{1}$, Dong Yang ${ }^{1}$, Yanming Chen ${ }^{1}$, Liping Cao ${ }^{1}$, Radu Custelcean ${ }^{2}$, Jiří Hostaš ${ }^{3,4}$, Pavel Hobza ${ }^{3,5}$, Robert Glaser ${ }^{6}$, Yao-Yu Wang ${ }^{1}$, Xiao-Juan Yang ${ }^{1} \&$ Biao Wu ${ }^{1}$

In nature, proteins have evolved sophisticated cavities tailored for capturing target guests selectively among competitors of similar size, shape, and charge. The fundamental principles guiding the molecular recognition, such as self-assembly and complementarity, have inspired the development of biomimetic receptors. In the current work, we report a self-assembled triple anion helicate (host 2 ) featuring a cavity resembling that of the choline-binding protein ChoX, as revealed by crystal and density functional theory (DFT)-optimized structures, which binds choline in a unique dual-site-binding mode. This similarity in structure leads to a similarly high selectivity of host $\mathbf{2}$ for choline over its derivatives, as demonstrated by the NMR and fluorescence competition experiments. Furthermore, host $\mathbf{2}$ is able to act as a fluorescence displacement sensor for discriminating choline, acetylcholine, L-carnitine, and glycine betaine effectively.

\footnotetext{
${ }^{1}$ Key Laboratory of Synthetic and Natural Functional Molecule Chemistry of the Ministry of Education, College of Chemistry and Materials Science, Northwest University, 710069 Xi'an, China. ${ }^{2}$ Chemical Sciences Division, Oak Ridge National Laboratory, Oak Ridge, TN 37831-6119, USA. ${ }^{3}$ Institute of Organic Chemistry and Biochemistry, 16010 Prague 6, Czech Republic. ${ }^{4}$ Department of Physical and Macromolecular Chemistry, Faculty of Science, Charles University in Prague, Albertov 6 12843, Czech Republic. ${ }^{5}$ Department of Physical Chemistry, Regional Centre of Advanced Technologies and Materials, Palacký University, 77146 Olomouc, Czech Republic. ${ }^{6}$ Department of Chemistry, Ben-Gurion University of the Negev, 84105 Beer-Sheva, Israel.

Correspondence and requests for materials should be addressed to B.W. (email: wubiao@nwu.edu.cn)
} 
C holine is an essential precursor for the synthesis of various important bio-functional molecules, such as the neurotransmitter acetylcholine, membrane lipid phosphatidylcholine, and osmoprotectant glycine betaine ${ }^{1,2}$. Selective binding of choline is the first step of the biosynthesis of these substances. In Sinorhizobium meliloti, a plant root-associated bacterium, the choline-binding protein ChoX has evolved to capture choline among competitors such as acetylcholine and glycine betaine $e^{2}$. Given the fact that all these compounds possess the same trimethylammonium head and a slightly different tail, their specific binding is quite challenging. The molecular basis for choline recognition was revealed by the crystal structure of $\mathrm{Ch}^{+} \subset$ ChoX (Protein Data Bank code 2reg) ${ }^{2}$, where an "aromatic box" (site-I) provides the main binding affinity for the trimethylammonium head through cation $-\pi$ interactions ${ }^{3-7}$, and two carboxyl groups (site-II) generate the critical differences in affinity for discriminating these analogues. Such a dual-sitebinding mode is a common feature of various binding proteins for choline and its derivatives ${ }^{8-10}$.

The pursuit for biomimetic receptors is an important engine driving the progress of supramolecular chemistry ${ }^{11,12}$. To this end, the naturally assembled protein cavity, which is essential for guest binding, has inspired the synthesis of artificial mimics, either through self-assembly of simple, well-designed building units $^{13-16}$ or through organic synthesis ${ }^{17-22}$. Development of this field is driven by promising applications ${ }^{23}$ of these systems in supramolecular catalysis ${ }^{24-29}$, protein binding 3 , 30, cellar imaging $^{31}$, and bio-process monitoring ${ }^{32}$. Although strong binding of choline by artificial receptors has been widely reported ${ }^{33-35}$, good selectivity for choline has not yet been achieved ${ }^{36-38}$. In nature, the ChoX protein is a specific high-affinity choline transporter and various choline derivatives present no or much weaker binding affinity. For instance, its binding for choline is 54-fold stronger than for acetylcholine, which is the strongest competitor ${ }^{1 \mathrm{a}}$. However, most artificial mimics display no obvious discrimination between them, and the reported selectivity ( $\left.K_{\text {choline }} / K_{\text {acetylcholine }}\right)$, to the best of our knowledge, is no more than three ${ }^{37}$.

We have recently developed a new strategy towards the construction of supramolecular architectures, wherein anion coordination chemistry ${ }^{39-42}$ is employed instead of the widely utilized metal coordination to drive the supramolecular assembly ${ }^{43-49}$. Various supramolecular structures have been obtained, including triple helicates ${ }^{43}, 44$ and tetrahedral cages $^{45,46}$. The negatively charged cavity make these anion-based assemblies potential receptors for positively charged species, including important biomolecules such as choline and other methylated substrates 3,50 .

Herein, we report a phosphate coordination-based triple helicate receptor functionalized with an aromatic box resembling the dual-site-binding mode of ChoX protein to achieve enhanced selectivity to choline. This receptor is developed as a fluorescence displacement sensor capable of discriminating choline from other structural analogues, which paves a way for potential applications in biological systems.

\section{Results}

Crystal structure of host 1 . Our previous studies ${ }^{43}, 44$ demonstrated that the properly spaced bis-bisurea ligands $\mathbf{L}^{\mathbf{1 a}}$ and $\mathbf{L}^{\mathbf{1 b}}$ (Fig. 1a) can readily form the $\mathrm{A}_{2} \mathrm{~L}_{3}(\mathrm{~A}=$ anion, $\mathrm{L}=$ ligand $)$ triple helicates when coordinated with $\mathrm{PO}_{4}{ }^{3-}$ ions. As a continuous effort to functionalize this type of assembly, ligand $\mathbf{L}^{2}$ was synthesized to create an aromatic box with its "V" shaped 4,4'-methylenebis(phenyl) linker upon formation of the helicate. This approach proved successful, leading to the
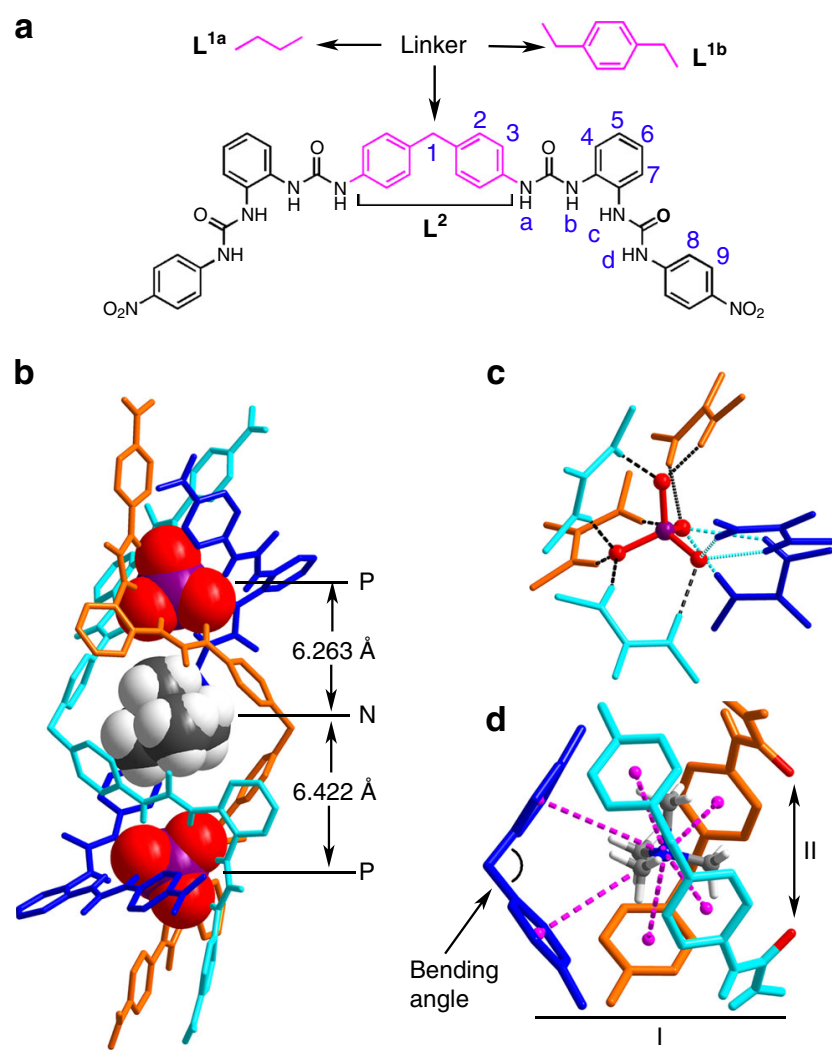

Fig. 1 Structure of a ChoX-mimicking triple anion helicate receptor. a Structures of bis-bisurea ligands $\mathbf{L}^{\mathbf{1} \mathbf{a}}, \mathbf{L}^{\mathbf{1}}$, and $\mathbf{L}^{\mathbf{2}}$ that can readily form the $A_{2} L_{3}(A=$ anion, $L=$ ligand) triple helicates when coordinated with $\mathrm{PO}_{4}{ }^{3-}$ ions. b Crystal structure of complex $\mathbf{1},(\mathrm{TMA})_{5}[(\mathrm{TMA}) \subset$

$\left.\left(\mathrm{PO}_{4}\right)_{2}\left(\mathbf{L}^{\mathbf{2}}\right)_{3}\right]$ ( $C=$ encapsulated by; only an $M$ enantiomer is shown; other counter cations, solvent molecules, and non-acidic protons are omitted for clarity); c Hydrogen bonds formed between a $\mathrm{PO}_{4}{ }^{3-}$ ion and six urea units; d The aromatic box (site-I) trapping a $\mathrm{TMA}^{+}$through cation- $\pi$ interactions (purple-dashed lines) and a potential hydrogen-bonding site (II), which together resembles the structure of $\mathrm{Ch}^{+} \subset \mathrm{ChoX}$

crystal structure of complex $\mathbf{1}$, (TMA $)_{5}\left[(\mathrm{TMA}) \subset\left(\mathrm{PO}_{4}\right)_{2}\left(\mathrm{~L}^{2}\right)_{3}\right]$ (Fig. 1b), comprising a triple helicate that contains a binding cavity flanked by six phenyl rings of the three $4,4^{\prime}$-methylenebis (phenyl) linkers, which traps a tetramethylammonium $\left(\mathrm{TMA}^{+}\right)$cation inside. Each $\mathrm{PO}_{4}{ }^{3-}$ center is coordinated by six urea units (Fig. 1c), four of which (shown in turquoise and orange) are arranged optimally along edges of the tetrahedral anion, and the remaining two (shown in blue) alternatively occupy two adjacent oxygen vertices, forming overall 12 hydrogen bonds to phosphate (dashed lines, $\mathrm{N} \bullet \bullet \mathrm{O}$ distances range from 2.681 to $3.213 \AA$, average $2.796 \AA$; $\mathrm{N}-\mathrm{H} \bullet \bullet \bullet \mathrm{O}$ angles from $141^{\circ}$ to $178^{\circ}$, average $156^{\circ}$; see Supplementary Table 1). The encapsulated $\mathrm{TMA}^{+}$ion is positioned close to the middle point of the two $\mathrm{PO}_{4}{ }^{3-}$ ions (with $\mathrm{P} \bullet \bullet \mathrm{N}$ distances of 6.263 and $6.422 \AA$, Fig. 1b). Besides the electrostatic interactions, $\mathrm{TMA}^{+}$guest is further stabilized by cation $-\pi$ interactions with the six phenyl rings of the linkers (purple-dashed lines, N.••centroid distances: $4.295-4.808 \AA$, average $4.535 \AA$, Fig. 1d, see also Supplementary Fig. 1). Noticeably, the triple helical structure of the inclusion complex $\mathbf{1}$ is not $\mathrm{C}_{3}$-symmetric and its cavity appears as a bowl-shaped pocket, where one of the ligands (Fig. 1d, blue, bending angle $114^{\circ}$ ) defines the bottom and the other two (turquoise and orange, bending angle $112^{\circ}$ ) circle a mouth decorated by two urea carbonyl groups (5.091 ̊̊ apart). 
a<smiles>[Y]OC[C@H](C)[N+](C)(C)C[C@H](O)CC(=O)[O-]</smiles>

b

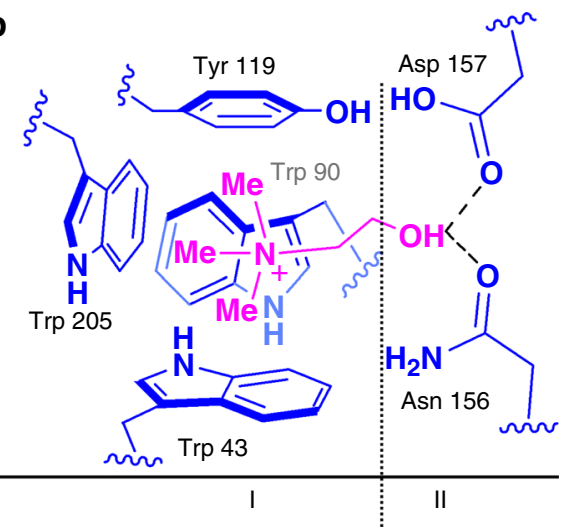

Fig. 2 The recognition mode of choline-binding protein ChoX. a Structures of choline and its derivatives, showing that they possess the same trimethylammonium head and a slightly different tail. b ChoX exhibits a synergistic dual-site-binding mode, where an "aromatic box" (site-I) provides the binding affinity for the trimethylammonium head, and two carboxyl groups (site-II) generate the critical differences in affinity for discriminating structural analogues $^{2}$

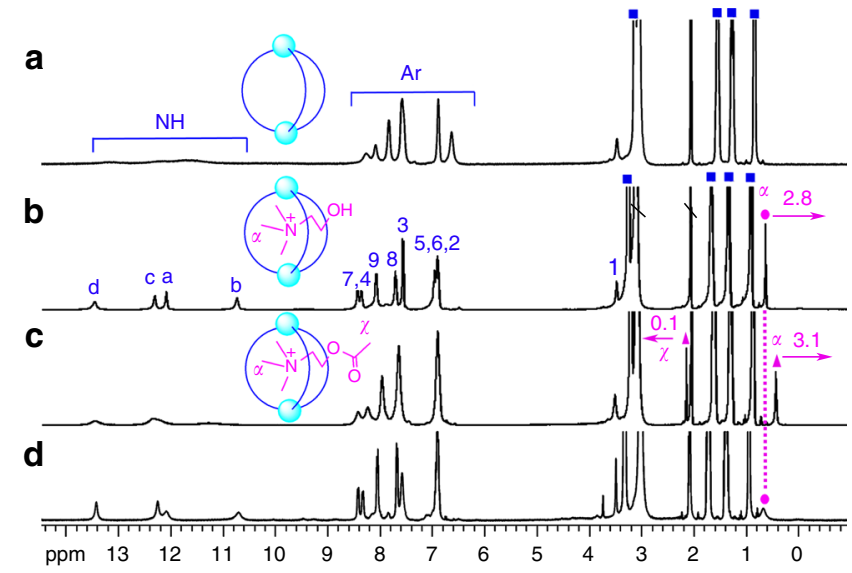

Fig. $3^{1} \mathrm{H}$ NMR spectra demonstrating complexation of different guests by host 2. a ${ }^{1} \mathrm{H}$ NMR (acetone- $d_{6} / 1.5 \% \mathrm{H}_{2} \mathrm{O}, 400 \mathrm{MHz}$ ) spectra of host 2 alone and in the presence of 1 equiv. of $\mathbf{b} \mathrm{Ch} \bullet \mathrm{Cl}, \mathbf{c} \mathrm{ACh} \bullet \mathrm{Cl}$, and in coexistence of 1 equiv. of $\mathbf{d} \mathrm{Ch} \bullet \mathrm{Cl}, \mathrm{ACh} \bullet \mathrm{Cl}, \mathrm{LC}$, and $\mathrm{GB}$ (blue squares TBA $\mathrm{T}^{+}$, magenta circles $\mathrm{Ch}^{+}$, magenta triangles $\mathrm{ACh}^{+}$, \ solvent residue; insets show representative pictures of free host $\mathbf{2}$ and host-guest inclusion complexes)

It was noticed that while $\mathrm{TMA}^{+}$is same with the trimethylammonium head of choline and its derivatives (Fig. 2a), the structure of complex 1 resembles that of $\mathrm{Ch}^{+} \subset \mathrm{ChoX}$ (Fig. 2b) with an aromatic box (I, six phenyl groups) and a hydrogenbonding site (II) and therefore prompted us to investigate its binding properties towards choline and its derivatives.

Host-guest studies of host 2. Considering that the counter cation $\mathrm{TMA}^{+}$in complex $\mathbf{1}$ will introduce competition, a new complex 2 [TBA $]_{6}\left[\left(\mathrm{PO}_{4}\right)_{2}\left(\mathbf{L}^{2}\right)_{3}\right]$ (host 2) was thus prepared, wherein $\mathrm{TBA}^{+}$(tetrabutylammonium) was employed as the counter cation, which is too large to be encapsulated in the helicate's cavity (Supplementary Table 2). High-resolution electrospray ionization mass spectrometry (HRMS) confirmed the formation of a complex with the $\left(\mathrm{PO}_{4}\right)_{2}\left(\mathbf{L}^{\mathbf{2}}\right)_{3}$ stoichiometry. Specifically, the observed $\mathrm{m} / \mathrm{z}$ peak for $\left[\left(\mathrm{L}^{2}\right)_{3}\left(\mathrm{PO}_{4}\right)_{2}(\mathrm{TBA})_{2} \mathrm{H}_{2}\right]^{2-}(1530.1376)$ is nearly identical to the predicted value (1530.1322), whereas its isotopic-splitting pattern is also in excellent agreement with that from the simulation (Supplementary Fig. 2). a

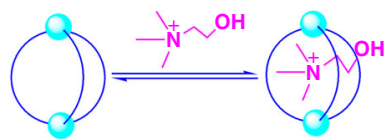

b

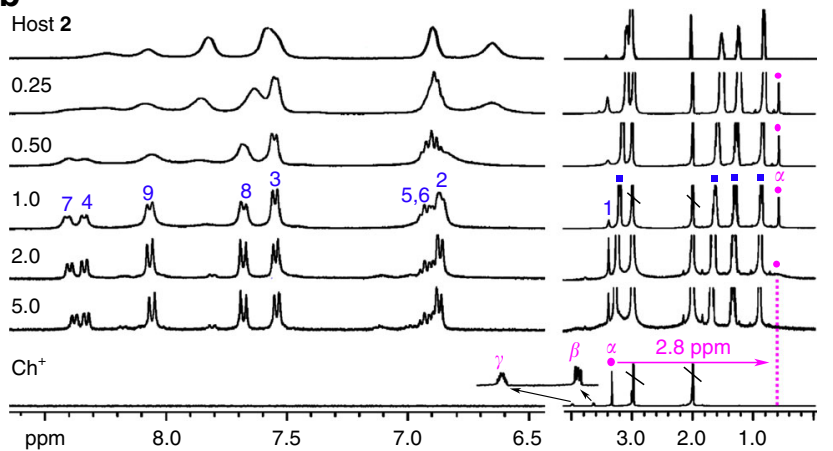

Fig. 4 Studies of the complexation process of choline by host $\mathbf{2}$. a Scheme of the equilibrium involved in the binding of $\mathrm{Ch} \bullet \mathrm{Cl}$ by host $\mathbf{2}$. $\mathbf{b}$ Stacking ${ }^{1} \mathrm{H}$ NMR (acetone- $d_{6} / 1.5 \% \mathrm{D}_{2} \mathrm{O}, 400 \mathrm{MHz}$ ) spectra of host 2

$(\mathrm{TBA})_{6}\left[\left(\mathrm{PO}_{4}\right)_{2}(\mathbf{L})_{3}\right]$ alone and in the presence of $\mathrm{Ch} \bullet \mathrm{Cl}$ (equiv. is labeled by numbers), and the spectrum of free $\mathrm{Ch} \bullet \mathrm{Cl}$ (blue squares $\mathrm{TBA}^{+}$, magenta circles $\mathrm{Ch}^{+}, \backslash$ solvent residue)

The binding of choline and potential competitors by host 2 was evaluated by ${ }^{1} \mathrm{H}$ NMR spectroscopy in acetone- $d_{6} / 1.5 \%$ $\mathrm{H}_{2} \mathrm{O}$, by adding 1 equiv. of choline $\left(\mathrm{Ch}^{+}\right)$, acetylcholine $\left(\mathrm{ACh}^{+}\right)$, glycine betaine (GB) and L-carnitine (LC), respectively (Fig. 3). Host 2 alone showed a set of broad signals (Fig. 3a), whereas in the presence of one equivalent of $\mathrm{Ch}^{+}$, all signals turned sharp and that of trimethylammonium protons $(\mathrm{H} \alpha)$ experienced a significant upfield shift of $2.8 \mathrm{ppm}$, indicating that $\mathrm{Ch}^{+}$was encapsulated in the shielding aromatic cavity of host 2 (Fig. 3b). Two-dimensional NMR spectroscopy provided further evidence for the encapsulation by the clear ${ }^{1} \mathrm{H}_{-}{ }^{1} \mathrm{H}$ NOE (nuclear Overhauser effect) correlations between $\mathrm{H} \alpha$ of $\mathrm{Ch}^{+}$and the phenylene protons (H3) of the linker of $\mathbf{L}^{\mathbf{2}}$ (see Fig. 1a for proton numbering, Supplementary Figs. 3 and 4). Moreover, HRMS confirmed the identity of this host-guest assembly by a group of $\mathrm{m} / z$ peaks of $\left[\left(\mathrm{L}^{2}\right)_{3}\left(\mathrm{PO}_{4}\right)_{2}(\mathrm{TBA})_{x}(\mathrm{Ch})_{y} \mathrm{H}_{z}\right]^{2-}(x, y, z=0,1,2$, or 3) (Supplementary Fig. 5). 

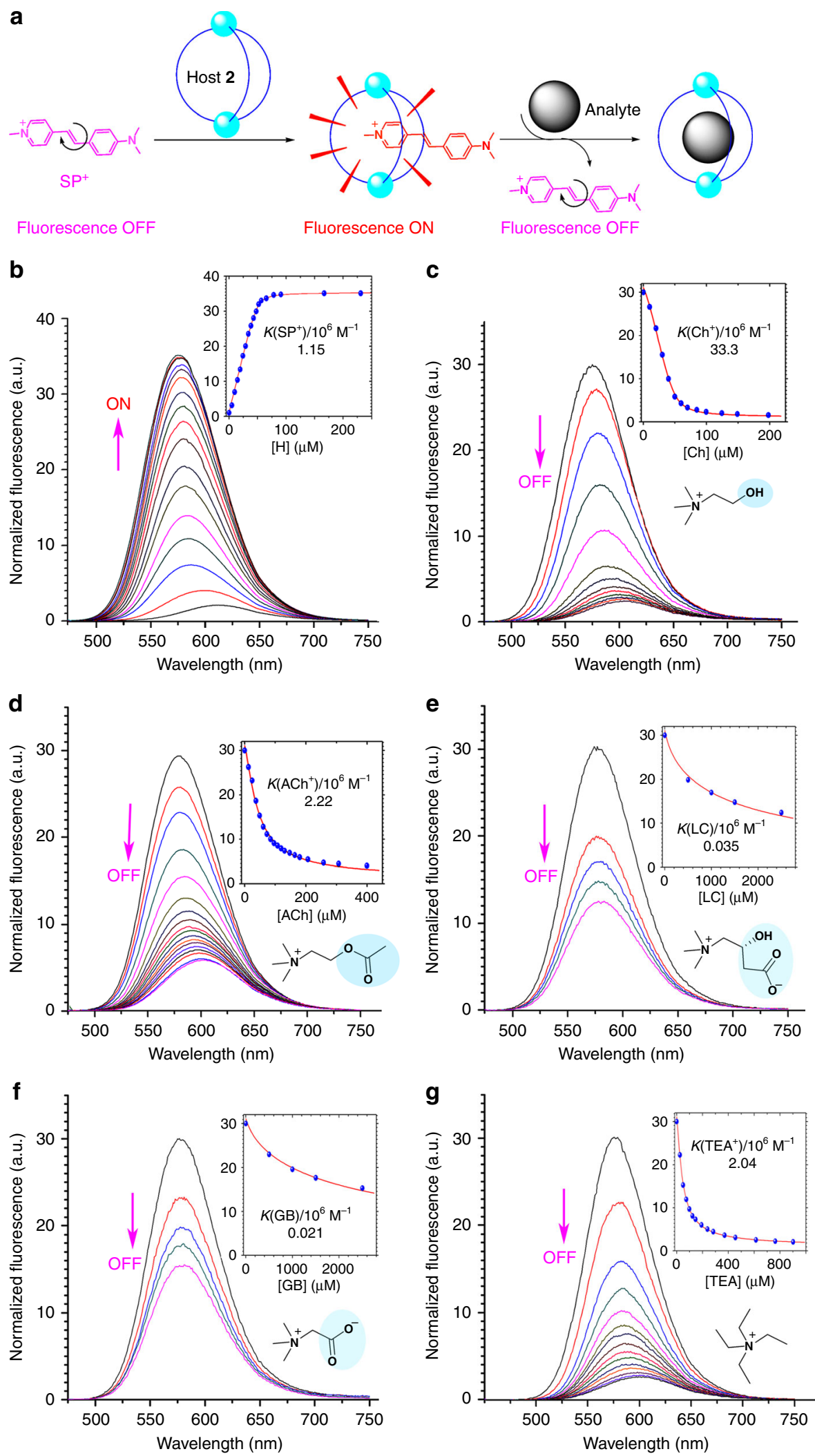

Fig. 5 Determination of binding constants of host $\mathbf{2}$ for guests by fluorescence titrations. a Principle of fluorescence "switch-off" displacement assay for analyte sensing. b Emission spectra of $50 \mu \mathrm{M} \mathrm{SP \bullet l} \mathrm{before} \mathrm{and} \mathrm{after} \mathrm{addition} \mathrm{of} \mathrm{aliquot} \mathrm{equiv.} \mathrm{of} \mathrm{host} \mathbf{2}$ (H2), showing a fluorescence "switch on" response. c Emission spectra of $\mathrm{SP}^{+} / \mathbf{H} \mathbf{2}(50 \mu \mathrm{M} / 50 \mu \mathrm{M})$ before and after addition of aliquot equiv. of $\mathrm{Ch} \bullet \mathrm{Cl}, \mathbf{d ~ A C h \bullet C l , ~ e ~ L C , ~} \mathbf{f} \mathrm{GB}$, and $\mathbf{g} \mathrm{TEA} \bullet \mathrm{Cl}$, respectively, showing a fluorescence "switch-off" response. All spectra were recorded in acetone $/ 1.5 \% \mathrm{H}_{2} \mathrm{O}$ with $\lambda_{\mathrm{ex}}=470 \mathrm{~nm}$. Insets show structures of analytes with the "tail" highlighted, and the corresponding association constants determined by fitting the titration curves at $\lambda_{\mathrm{em}}=575 \mathrm{~nm}$ (blue dots) to a 1:1 (host : guest) binding mode by the Dynafit program (error $<10 \%$ ) 


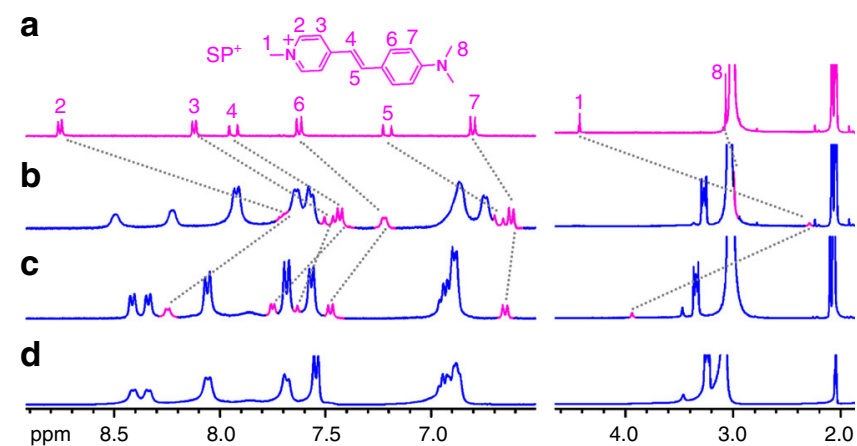

Fig. 6 Displacement binding of $\mathrm{SP}^{+}$by $\mathrm{Ch}^{+}$. a ${ }^{1} \mathrm{H}$ NMR $(400 \mathrm{MHz}$, acetone$d_{6} / 1.5 \% \mathrm{H}_{2} \mathrm{O}$ ) spectra of a $1 \mathrm{mM} \mathrm{SP} \bullet$ (inset shows the structure), $\mathbf{b}$ host $\mathbf{2} / \mathrm{SP} \bullet \mathrm{I}(1 / 1$ equiv.), $\mathbf{c}$ host $\mathbf{2} / \mathrm{SP} \bullet \mathrm{I} / \mathrm{Ch} \bullet \mathrm{Cl}(1 / 1 / 1$ equiv.), and $\mathbf{d}$ host $\mathbf{2}$ /

$\mathrm{Ch} \bullet \mathrm{Cl}\left(1 / 1\right.$ equiv.). Chemical shifts of protons of $\mathrm{SP}^{+}$upon complexation and decomplexation were labeled by gray dashed lines

Among the other three tested guests, GB and LC showed no significant binding (Supplementary Fig. 6) and only $\mathrm{ACh}^{+}$ induced obvious changes in the NMR spectrum though the resulted signals remained broad (Fig. 3c), which is indicative of low symmetry of the host-guest complex. The proton signal of the trimethylammonium fragment $(\mathrm{H} \alpha)$ of $\mathrm{ACh}^{+}$shifted upfield by $3.1 \mathrm{ppm}$, whereas the methyl protons of the acetyl group $(\mathrm{H} \chi)$ showed a slight downfield shift ( $\Delta \delta=0.1 \mathrm{ppm})$, implying that this "tail" group is positioned out of the shielding cage. In both cases of $\mathrm{Ch}^{+}$and $\mathrm{ACh}^{+}$, the formation of a single host-guest species was confirmed by DOSY (diffusion-ordered nuclear magnetic resonance spectroscopy) spectra, in which the diffusion coefficients of the guest and host $\mathbf{2}$ were very similar (Supplementary Figs. 7,8 ). In addition, competition experiments showed that the spectrum of host $2 / \mathrm{Ch}^{+}$was only slightly altered by the addition of one equiv. of competitors $\mathrm{ACh}^{+}, \mathrm{GB}$, and $\mathrm{LC}$, indicating that $\mathrm{Ch}^{+}$is the most favorable guest of host 2 among these four biomolecules (Fig. 3d).

Titration experiments revealed that either $\mathrm{Ch}^{+}$(Fig. 4) or $\mathrm{ACh}^{+}$ (Supplementary Fig. 9) was bound in a 1:1 (host:guest) binding mode with a similar intermediate exchange on the NMR timescale ${ }^{51}$. Taking $\mathrm{Ch}^{+}$as an example, in the first step within the addition of 0-1 equiv. of $\mathrm{Ch}^{+}$, increasing amounts of the free host 2 bound the $\mathrm{Ch}^{+}$as demonstrated by gradual shifting of its broad signals that became sharp and saturated when guest/host ratio reached 1:1. Meanwhile, the methyl proton signal of $\mathrm{Ch}^{+}$ kept sharp and stayed at $0.6 \mathrm{ppm}$, indicating this guest ion is predominantly encapsulated in the cage of $\mathbf{2}$. In the second step when gradually increasing the amount of $\mathrm{Ch}^{+}$from 1 to 5 equiv., the signals of host 2 showed no significant changes, whereas the $\mathrm{H} \alpha$ signal of $\mathrm{Ch}^{+}$at $0.6 \mathrm{ppm}$ turned broad until it disappeared, implying that the excessive $\mathrm{Ch}^{+}$guest ions remained outside of the cage and engaged in intermediate exchange with the encapsulated ones.

Binding constants determination. Such intermediate exchange properties in the binding of $\mathrm{Ch}^{+}$and $\mathrm{ACh}^{+}$prohibit the direct determination of association constants by fitting a titration curve (in the case of fast exchange) or by estimating the concentrations of host and guest based on integral ratios (slow exchange). Hence, to quantitatively evaluate the selectivity of host 2 for $\mathrm{Ch}^{+}$over $\mathrm{ACh}^{+}$, it is necessary to carry out competition experiments with a suitable guest as the reference, which should have a determinable association constant and is bound by host 2 with comparable strength as $\mathrm{Ch}^{+}$and $\mathrm{ACh}^{+}$. With this in mind, three guest ions $\mathrm{TMA}^{+}, \mathrm{TEA}^{+}$, and $\mathrm{TPA}^{+}$were screened by titration with host 2 .
$\mathrm{TMA}^{+}$was found to bind in intermediate exchange (Supplementary Figs. 10-12) and $\mathrm{TPA}^{+}$showed no obvious binding (Supplementary Fig. 13). Fortunately, $\mathrm{TEA}^{+}$was bound in fast exchange (Supplementary Figs. 14-16), and the association constant was determined as $K>10^{4} \mathrm{M}^{-1}$ (the limit for accurate determination using this method) by fitting the shift profile of the $\mathrm{CH}_{3}$ proton to a 1:1 mode with WinEQNMR program (Supplementary Figs. 17, 18 $)^{52}$. By taking $\mathrm{TEA}^{+}$as a standard guest, the binding constants of $\mathrm{TMA}^{+}, \mathrm{Ch}^{+}$, and $\mathrm{ACh}^{+}$relative to $\mathrm{TEA}^{+}$ were estimated to be $17.4 \mathrm{~K}\left(\mathrm{TEA}^{+}\right), 24.1 \mathrm{~K}\left(\mathrm{TEA}^{+}\right)$, and $1.2 \mathrm{~K}$ $\left(\mathrm{TEA}^{+}\right)$, respectively (Supplementary Table 3; Supplementary Fig. 19). Thus the binding affinity of $\mathrm{Ch}^{+}$by host 2 appears to be about 20-fold stronger than that of $\mathrm{ACh}^{+}$. On the other hand, the binding of GB and LC was too weak to compete with $\mathrm{TEA}^{+}(K$ « $K$ $\left(\mathrm{TEA}^{+}\right)$), and the selectivity of host 2 for the four was in the order of $\mathrm{Ch}^{+}>\mathrm{ACh}^{+}>>\mathrm{GB}, \mathrm{LC}$.

Moreover, efforts were also devoted to calculate the association constants of host $\mathbf{2}$ with the guests in a more accurate way based on fluorescence titrations. As neither host $\mathbf{2}$ nor the tested guests are fluorescent, a fluorescence displacement sensor was developed based on the inclusion complex, $\mathrm{SP}^{+} \subset 2,\left(\mathrm{SP}^{+}=4\right.$-(4'-dimethylamino)styryl-1-methylpyridinium), which can signal guest binding by displacement of the $\mathrm{SP}^{+}(\text {Fig. } 5 \mathrm{a})^{53}$. The formation of host 2-SP ${ }^{+}$complex and subsequently displacement of $\mathrm{SP}^{+}$by $\mathrm{Ch}^{+}$ were firstly confirmed by ${ }^{1} \mathrm{H}$ NMR spectra (Fig. 6; Supplementary Table 4). The pyridinium $\mathrm{N}$-methyl signal (H1) of $\mathrm{SP}^{+}$ experienced a significant upfield shift of $2.1 \mathrm{ppm}$, indicating $\mathrm{SP}^{+}$ was encapsulated in the shielding aromatic cavity of host $\mathbf{2}$. Phenyl and alkenyl signals of $\mathrm{SP}^{+}$also experienced dramatic upfield shifts (H2-7) $0.2-1.1 \mathrm{ppm})$, whereas the proton signals of dimethylamino (H8) showed only a slight upfield shift $(0.08 \mathrm{ppm})$, suggesting that this "tail" group is positioned out of the shielding cage. The encapsulated $\mathrm{SP}^{+}$was readily replaced by one equiv. of subsequently added $\mathrm{Ch}^{+}$, which induced mainly recovery of the signals of the free $\mathrm{SP}^{+}$and formation of a $\mathrm{Ch}^{+} \mathrm{C}$ host 2 complex.

Fluorescence titration of a $50 \mu \mathrm{M}$ solution of $\mathrm{SP}^{+}$with host 2 was then performed, which induced an increase of the fluorescence by 35 -fold (fluorescence $\mathrm{ON}$ ) and a $37 \mathrm{~nm}$ hypsochromic shift $(612 \mathrm{~nm}$ to $575 \mathrm{~nm})$ of the maximum emission (Fig. 5b). The $K\left(\mathrm{SP}^{+}\right)$was calculated as $1.15 \times 10^{6} \mathrm{M}^{-1}$ by fitting the titration curve of $\mathrm{SP}^{+} \subset 2$ with Dynafit program ${ }^{54}$ to a 1:1 mode, which was further confirmed by the Job's plot (Supplementary Fig. 20). Upon addition of tested guests to a solution of $\mathrm{SP}^{+} /$host $2(50 \mu \mathrm{M} / 50 \mu \mathrm{M})$, the fluorescence decreased (OFF) as a result of displacement of $\mathrm{SP}^{+}$and the corresponding association constants were thus obtained by fitting the titration curves to the 1:1 mode. The $K\left(\mathrm{Ch}^{+}\right)$and $K\left(\mathrm{ACh}^{+}\right)($Fig. 5 c, d) were $3.33 \times 10^{7} \mathrm{M}^{-1}$ and $2.22 \times 10^{6} \mathrm{M}^{-1}$, respectively, giving a selectivity of $K\left(\mathrm{Ch}^{+}\right) / K\left(\mathrm{ACh}^{+}\right)$as 15 , which is consistent with the value (20) obtained from NMR. Moreover, the high sensitivity of fluorescence changes (Fig. 5e, f) enables determination of $K(\mathrm{~GB})$ and $K(\mathrm{LC})$, which as mentioned above could not be measured by NMR competition with $\mathrm{TEA}^{+}$, as $2.1 \times 10^{4} \mathrm{M}^{-1}$ and $3.5 \times 10^{4} \mathrm{M}$ ${ }^{-1}$, respectively, and the selectivity was ranked as $\mathrm{Ch}^{+}>\mathrm{ACh}^{+}$ $>>\mathrm{GB} \approx \mathrm{LC}$. In addition, the $K\left(\mathrm{TEA}^{+}\right)$and $K\left(\mathrm{TMA}^{+}\right)$were determined as $2.04 \times 10^{6} \mathrm{M}^{-1}$ and $1.74 \times 10^{7} \mathrm{M}^{-1}$, respectively (Fig. 5g; Supplementary Fig. 21). These results match well with those obtained from NMR competition titrations (Supplementary Table 5).

Mechanism studies. The origin of the high selectivity of host 2 towards $\mathrm{Ch}^{+}$over $\mathrm{ACh}^{+}$was further investigated by DFT optimization of the structures of the corresponding inclusion complexes. $\mathrm{Ch}^{+} \subset 2$ (Fig. 7a) demonstrates a similar dual-site- 
a

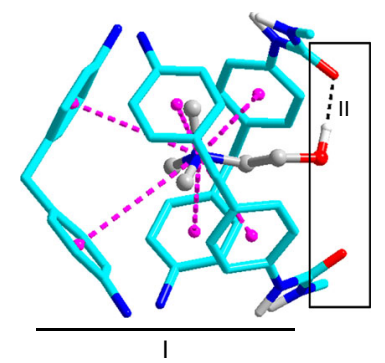

b
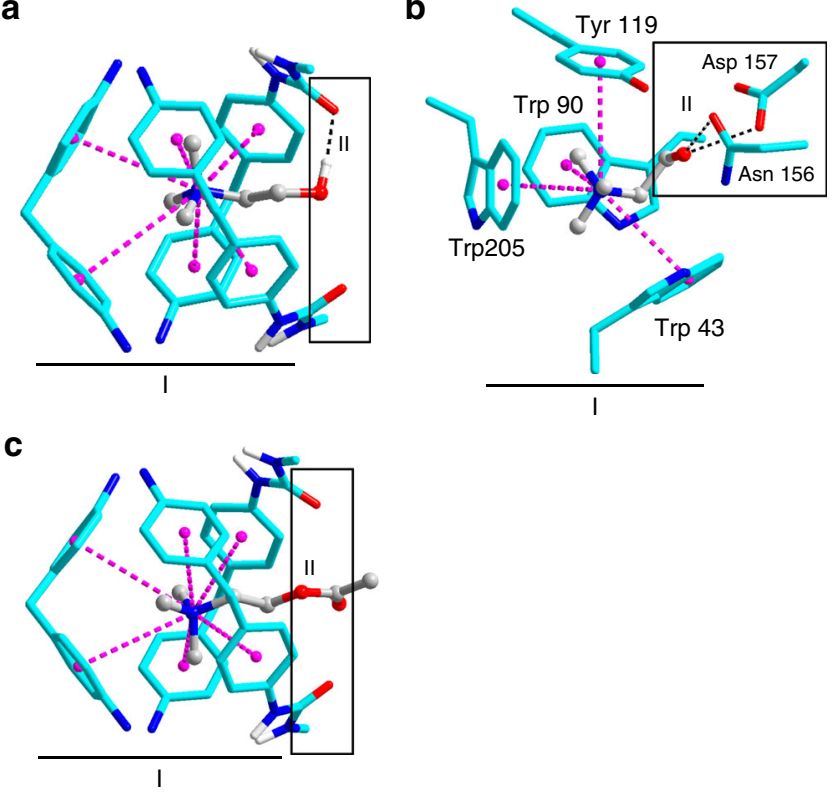

Fig. 7 Comparison of the binding modes for $\mathrm{Ch}^{+}$and $\mathrm{Ach}^{+}$in host $\mathbf{2}$ and ChoX. a DFT-optimized structure of $\mathrm{Ch}^{+} \subset \mathbf{2}$. b Crystal structure of $\mathrm{Ch}^{+} \subset$ ChoX (Protein Data Bank code 2reg) ${ }^{2}$. c DFT-optimized structure of

$\mathrm{ACh}^{+} \subset \mathbf{2}$. Binding sites are labeled as I and II, cation- $\pi$, and hydrogen bonding interactions are labeled as purple-dashed line and black-dashed line, respectively

binding mode to that of $\mathrm{Ch}^{+} \subset \mathrm{ChoX}$ (Fig. $\left.7 \mathrm{~b}\right)^{2}$, whereas $\mathrm{ACh}^{+} \subset$ 2 presents only a single binding at site-I but not at site-II, which was accounted for the discrimination of $\mathrm{Ch}^{+}$and $\mathrm{ACh}^{+}$(Fig. 7c) Specifically, at site-I of $\mathrm{Ch}^{+} \subset 2$, the aromatic box is composed of six phenyl groups with No..centroid distances ranging from 4.3 to $4.9 \AA$ (av. $4.7 \AA$, Supplementary Fig. 22), and in $\mathrm{Ch}^{+} \subset \mathrm{ChoX}$, the cage is surrounded by the aryl rings of three tryptophans and a single tyrosine residue (Trp43, Trp90, Trp205, and Tyr119) with No.*centroid distances of 4.2 to $4.5 \AA$ (av. $4.3 \AA$, Supplementary Fig. 23). At site-II of $\mathrm{Ch}^{+} \subset 2$, the hydrogen bond shows an $\mathrm{O} \cdots \mathrm{O}$ distance of $2.7 \AA$ and $\mathrm{O}-\mathrm{H} \cdots \mathrm{O}$ angle of $168^{\circ}$. Correspondingly in $\mathrm{Ch}^{+} \subset \mathrm{ChoX}$, there are two hydrogen bonds with $\mathrm{O} \bullet \mathrm{O}^{\circ} \mathrm{O}$ distances of 2.7 and $3 \AA$, respectively $(\mathrm{O}-\mathrm{H} \cdots \mathrm{O}$ angles not available). The DFT-optimized structure of the $\mathrm{ACh}^{+} \subset 2$ displays a similar aromatic box encapsulating the trimethylammonium head and the methyl protons of the acetyl group are extending out of the cavity, which is consistent with the results demonstrated by ${ }^{1} \mathrm{H}$ NMR (Fig. 3c). The No..centroid distances in $\mathrm{ACh}^{+} \subset 2$ are ranging from 4.3 to $4.9 \AA$ with an average of $4.6 \AA$ (Supplementary Fig. 24). In contrast to $\mathrm{Ch}^{+} \subset 2$, no hydrogen bond is formed in $\mathrm{ACh}^{+} \subset 2$ with the tail group, which results in a $2.8 \mathrm{kcal} \mathrm{mol}^{-1}$ weaker binding than that of $\mathrm{Ch}^{+}$(Supplementary Table 6). On the other hand, it is reasonable to hypothesize that binding of the zwitterionic guests, LC and GB, in a similar mode to that of $\mathrm{Ch}^{+}$should position the guest's carboxylate group in proximity to the negatively charged cavity and the two urea carbonyl residues (site-II). The resulting strong electrostatic repulsion is possibly responsible for the much weaker binding of GB and LC.

It should be noted that though DFT modeling has provided evidences that the selectivity of host $\mathbf{2}$ for $\mathrm{Ch}^{+}$over $\mathrm{ACh}^{+}$may arise from the additional secondary binding with the hydroxyl "tail", another factor, i.e., the smaller steric effect of $\mathrm{Ch}^{+}$than $\mathrm{ACh}^{+}$cannot be ruled out. To address this point, the $\mathrm{TMA}^{+}$was selected as a model for control experiments, which possesses a trimethylammonium head same as $\mathrm{Ch}^{+}$, whereas a smaller tail
(-Me vs $-\mathrm{CH}_{2} \mathrm{CH}_{2} \mathrm{OH}$ ). If there is no hydrogen bonding at site-II, the binding of TMA ${ }^{+}$is supposed to be stronger than $\mathrm{Ch}^{+}$due to its smaller steric effect. On the contrary, the association constant was determined as $K\left(\mathrm{TMA}^{+}\right)=0.7 K\left(\mathrm{Ch}^{+}\right)$by $\mathrm{NMR}$ and fluorescence titrations (Supplementary Fig. 21; Supplementary Table 5). This was rationalized by the proposed secondary hydrogen bonding at site-II, which provides positive binding energy to overcome the negative steric effect and induces a stronger binding than $\mathrm{TMA}^{+}$.

\section{Discussion}

In conclusion, we report a phosphate coordination-based triple helicate as a type of supramolecular host with an aromatic box for guest binding. Of particular significance is this host system displays a unique high selectivity towards choline over the closely related acetylcholine $\left(K_{\text {choline }} / K_{\text {acetylcholine }}>15\right)$. Mechanism studies demonstrated that the synergetic dual-site binding of both the trimethylammonium head and hydroxyl-tail is the most critical reason for its selectivity. On the basis of this property, the triple anion helicate has been developed as a fluorescence displacement sensor capable of effectively discriminating choline, acetylcholine, L-carnitine and glycine betaine. We are currently modifying the system to exploit its potential applications in cellar imaging ${ }^{31}$, monitoring biomembrane transport ${ }^{32}$, recognition of proteins ${ }^{55}$, and tracking enzyme's activity ${ }^{56-59}$, etc.

\section{Methods}

General information. All reagents were obtained commercially and used without further purification. The indicator dye, 4-(4-dimethylaminostyryl)-1-methylpyridinium iodide $(\mathrm{SP} \bullet \mathrm{I})$, was synthesized following a published procedure ${ }^{60}$. All NMR spectra were obtained at $20^{\circ} \mathrm{C}$ by using Bruker AVANCE III- $400 \mathrm{MHz}$ or $-500 \mathrm{MHz}$ spectrometers. ${ }^{1} \mathrm{H}$ and ${ }^{13} \mathrm{C}$ NMR chemical shifts were reported relative to residual solvent peaks ( ${ }^{1} \mathrm{H}$ NMR: $2.50 \mathrm{ppm}$ for DMSO- $d_{6}, 2.05 \mathrm{ppm}$ for acetone$d_{6} ;{ }^{13} \mathrm{C}$ NMR: 39.52 for DMSO- $d_{6}$ ). Infrared (IR) spectra were recorded on a Bruker EQUIOX-55 spectrometer. High-resolution mass spectra were performed with an Orbitrap mass spectrometer (Q-Exactive, Thermo Scientific, San Jose, CA) for complex 1 and a Bruker micrOTOF-Q II ESI-Q-TOF LC/MS/MS spectrometer for complex 2 and complex $2 / 1$ equiv. Ch $\bullet \mathrm{Cl}$. Fluorescence spectra $\left(\lambda_{\mathrm{ex}}=470 \mathrm{~nm}\right)$ were recorded on a Horiba FL1039A/40 A spectrophotometer in a $1 \mathrm{~cm}$ quartz cell.

Synthesis of $\mathbf{L}^{\mathbf{2}}$. 1-(2-Aminophenyl)-3-(4-nitrophenyl)urea ${ }^{44}(1.07 \mathrm{~g}, 3.9 \mathrm{mmol})$ and methylene di-p-phenylene diisocyanate $(0.47 \mathrm{~g}, 1.9 \mathrm{mmol})$ in $200 \mathrm{ml}$ THF were refluxed overnight and the precipitate was filtered off and washed several times with acetone and diethyl ether and then dried over vacuum to get the analytically pure product as a yellow powder $(1.33 \mathrm{~g}, 88 \%) .{ }^{1} \mathrm{H}$ NMR $\left(400 \mathrm{MHz}, \mathrm{DMSO}-d_{6}\right.$, ppm): $\delta 9.84(\mathrm{~s}, 1 \mathrm{H}, \mathrm{NH}), 9.00(\mathrm{~s}, 1 \mathrm{H}, \mathrm{NH}), 8.26(\mathrm{~s}, 1 \mathrm{H}, \mathrm{NH}), 8.19(\mathrm{~d}, J=8.0 \mathrm{~Hz}$, $2 \mathrm{H}, \mathrm{H} 9), 8.06(\mathrm{~s}, 1 \mathrm{H}, \mathrm{Hd}), 7.71(\mathrm{~d}, J=8.0 \mathrm{~Hz}, 2 \mathrm{H}, \mathrm{H} 8), 7.64(\mathrm{~d}, J=8.0 \mathrm{~Hz}, 1 \mathrm{H}, \mathrm{H} 7)$, $7.54(\mathrm{~d}, J=8.0 \mathrm{~Hz}, 1 \mathrm{H}, \mathrm{H} 4), 7.37$ (d, $J=8.0 \mathrm{~Hz}, 2 \mathrm{H}, \mathrm{H} 3), 7.11(\mathrm{~m}, 4 \mathrm{H}, \mathrm{H} 2, \mathrm{H} 5, \mathrm{H} 6)$, $3.80(\mathrm{~s}, 1 \mathrm{H}, \mathrm{H1}) .{ }^{13} \mathrm{C}$ NMR $\left(100 \mathrm{MHz}, \mathrm{DMSO}-d_{6}\right): 153.21(\mathrm{CO}), 152.78(\mathrm{CO})$, $146.62(\mathrm{C}), 140.98(\mathrm{C}), 137.67(\mathrm{C}), 135.12(\mathrm{C}), 132.20(\mathrm{C}), 130.17(\mathrm{C}), 128.96(\mathrm{CH})$ $125.19(\mathrm{CH}), 124.88(\mathrm{CH}), 123.83(\mathrm{CH}), 123.60(\mathrm{CH}), 118.50(\mathrm{CH}), 117.44(\mathrm{CH})$ (Supplementary Fig. 25). IR $\left(\mathrm{KBr}, \mathrm{v} / \mathrm{cm}^{-1}\right): 3266(\mathrm{NH}), 1653(\mathrm{CO}), 1588,1558$, $1498,1398,1313,1299\left(\mathrm{NO}_{2}\right), 1234,1179,1099,839,749,680,625$. HRMS: $\mathrm{m} / \mathrm{z}$ Calcd. for $[\mathrm{M}-\mathrm{H}], 793.2483$, found 793.2471 .

Self-assembly of (TMA) $)_{5}\left[(T M A) \subset\left(\mathbf{P O}_{4}\right)_{2}\left(\mathrm{~L}^{2}\right)_{3}\right]$ (complex 1$)$. $\mathrm{L}^{\mathbf{2}}(108 \mathrm{mg}$, $0.136 \mathrm{mmol})$ was reacted with 0.67 equiv. of (TMA $)_{3} \mathrm{PO}_{4}(181 \mu \mathrm{l} 0.5 \mathrm{M}$ solution, generated in situ from (TMA)OH and $\mathrm{H}_{3} \mathrm{PO}_{4}$ ) in acetonitrile $(5 \mathrm{ml})$. After stirring overnight at room temperature, a clear yellow solution was obtained. Slow vapor diffusion of diethyl ether into this solution provided yellow crystals of the inclusion complex 1 within one week (126 mg, 92\%). The identity of complex 1 was confirmed by HRMS (Supplementary Fig. 26).

Self-assembly of (TBA) ${ }_{6}\left[\left(\mathbf{P O}_{\mathbf{4}}\right)_{\mathbf{2}}\left(\mathrm{L}^{\mathbf{2}}\right)_{3}\right]$ (complex 2$) . \mathbf{L}^{2}(122 \mathrm{mg}, 0.154 \mathrm{mmol})$ was reacted with 0.67 equiv. of $(\mathrm{TBA})_{3} \mathrm{PO}_{4}(205 \mu \mathrm{l} 0.5 \mathrm{M}$ solution, generated in situ from (TBA)OH and $\mathrm{H}_{3} \mathrm{PO}_{4}$ ) in acetonitrile $(5 \mathrm{ml})$. After stirring overnight at room temperature, a clear yellow solution was obtained. Pouring this solution into $50 \mathrm{ml}$ of diethyl ether induced a yellow precipitate, which was collected through filtration and then dried over vacuum to get complex 2 as a yellow powder (182 mg, 88\%). The identity of complex 2 was confirmed by HRMS (Supplementary Fig. 2).

Crystallography and data analysis. Diffraction data were collected on a Bruker SMART APEX II diffractometer at $100 \mathrm{~K}$ with graphite-monochromated Mo K $\alpha$ 
radiation $(\lambda=0.71073 \AA$ ). An empirical absorption correction using SADABS was applied for the data. The structures were solved by direct methods using the SHELXS-2014 program. All non-hydrogen atoms were refined anisotropically by full-matrix least-squares on $F^{2}$ by the use of the program SHELXL-2014, and hydrogen atoms were included in idealized positions with thermal parameters equiv. to 1.2 times those of the atom to which they were attached.

NMR titrations. Given the poor solubility of the cationic guests (all used as chloride salts unless otherwise noted) in acetone, a stock solution of host complex 2 $\left(10 \mathrm{mM}, 100 \mathrm{mM}\right.$ in acetone- $\left.d_{6} / 1.5 \% \mathrm{D}_{2} \mathrm{O}\right)$ was titrated to a $2 \mathrm{mM}$ solution of the guest $\left(\mathrm{TMA}^{+}, \mathrm{TEA}^{+}, \mathrm{Ch}^{+}, \mathrm{Ach}^{+}\right.$) in acetone- $d_{6} / 1.5 \% \mathrm{D}_{2} \mathrm{O}$. Equivalents of the host were titrated as $0.2,0.5,1,2$, and 4 , and thus the titration spectra were obtained with equiv. of the guest as $5,2,1,0.5$, and 0.25 . Other samples for 2D NMR experiments (NOESY, DOSY, and correlation spectroscopy $=$ COSY) were prepared in acetone- $d_{6} / 1.5 \% \mathrm{H}_{2} \mathrm{O}$ with a $6 \mathrm{mM}$ solution of complex 2 .

Fluorescence titrations. Fluorescence titrations were performed at room temperature. In the fluorescence titrations of SP・I (dye) with host 2 (Fig. 5b), known amounts of host 2 were added to a $2 \mathrm{ml}$ solution of $50 \mu \mathrm{M} \mathrm{SP} \bullet \mathrm{I}$ in acetone- $1.5 \% \mathrm{H}_{2} \mathrm{O}$. To keep the concentration of dye as constant in the course of the titration, $1 \mathrm{mM}$ stock solutions of host were prepared with a $50 \mu \mathrm{M}$ solution of $[\mathrm{SP} \bullet \mathrm{I}]$ in acetone $-1.5 \% \mathrm{H}_{2} \mathrm{O}$. Similarly in the processes of displacement titrations, known amounts of competitors (analytes) were added successively to a $2 \mathrm{ml}$ solution of [host 2]/[SP・I] $(50 \mu \mathrm{M} / 50 \mu \mathrm{M})$ in acetone-1.5\% $\mathrm{H}_{2} \mathrm{O}$. To keep the concentration of host 2 and dye constant in the course of the titration, stock solutions of analytes $([\mathrm{TMA} \bullet \mathrm{Cl}]=1 \mathrm{mM},[\mathrm{Ch} \bullet \mathrm{Cl}]=2 \mathrm{mM},[\mathrm{TEA} \bullet \mathrm{Cl}]=$ $[\mathrm{ACh} \bullet \mathrm{Cl}]=5 \mathrm{mM})$ were prepared with a solution of [host 2]/[SP・I] $(50 \mu \mathrm{M} / 50$ $\mu \mathrm{M}$ ) in acetone-1.5\% $\mathrm{H}_{2} \mathrm{O}$. As GB and LC require much excessive amounts to induce significant fluorescence changes, the high-concentration stock solutions could not be prepared in [host 2]/[SP・I] $(50 \mu \mathrm{M} / 50 \mu \mathrm{M})$ in acetone- $1.5 \% \mathrm{H}_{2} \mathrm{O}$ due to the low solubility. Alternatively, $1.0 \mathrm{M}$ stock solutions in deionized water were utilized, which totally introduced $4 \mu \mathrm{l} \mathrm{H}_{2} \mathrm{O}(0.2 \%$ of the $2 \mathrm{ml}$ mother solution) during each titration course and the influence of this tiny amount of water was ignored.

Binding constants determination. In the NMR titrations, the binding constants of guests, $K(\mathrm{G})$, relative to $K\left(\mathrm{TEA}^{+}\right)$were estimated based on competition experiments. In the fluorescence titrations, they were determined by fitting titration curves at $\lambda_{\mathrm{em}}=575 \mathrm{~nm}$ to a 1:1 (host:guest) binding mode by Dynafit program $(\text { error }<10 \%)^{54}$

Molecular modeling. The DFT method, augmented with empirical dispersion term (D3), was utilized for the current study ${ }^{61-63}$.

Data availability. The X-ray crystallographic data for the structure of complex $\mathbf{1}$, $(\mathrm{TMA})_{5}\left[(\mathrm{TMA}) \subset\left(\mathrm{PO}_{4}\right)_{2}\left(\mathbf{L}^{2}\right)_{3}\right]$, is available at the Cambridge Crystallographic Data Centre (CCDC) with the deposition number CCDC 1517699; Supplementary methods of binding constants determination, molecular modeling, and additional data supporting the findings of this study are available in Supplementary Information file. Cartesian coordinates of the optimized geometries of $\mathrm{Ch}^{+} \subset 2$ and $\mathrm{ACh}$ ${ }^{+} \subset 2$ are available in Supplementary Data 1.

Received: 23 November 2016 Accepted: 4 August 2017

Published online: 16 October 2017

\section{References}

1. Dupont, L. et al. The Sinorhizobium meliloti ABC transporter Cho is highly specific for choline and expressed in bacteroids from Medicago sativa nodules. J. Bacteriol. 186, 5988-5996 (2004).

2. Oswald, C. et al. Crystal structures of the choline/acetylcholine substratebinding protein ChoX from Sinorhizobium meliloti in the liganded and unliganded-closed states. J. Biol. Chem. 283, 32848-32859 (2008).

3. Daze, K. D. \& Hof, F. The cation- $\pi$ interaction at protein-protein interaction interfaces: developing and learning from synthetic mimics of proteins that bind methylated lysines. Acc. Chem. Res. 46, 937-945 (2013).

4. Ma, J. C. \& Dougherty, D. A. The cation- $\pi$ interaction. Chem. Rev. 97, 1303-1324 (1997).

5. Salonen, L. M., Ellermann, M. \& Diederich, F. Aromatic rings in chemical and biological recognition: energetics and structures. Angew Chem. Int. Ed. 50, 4808-4842 (2011).

6. Schneider, H.-J. Binding mechanisms in supramolecular complexes. Angew Chem. Int. Ed. 48, 3924-3977 (2009).
7. Meyer, E. A., Castellano, R. K. \& Diederich, F. Interactions with aromatic rings in chemical and biological recognition. Angew Chem. Int. Ed. 42, 1210-1250 (2003).

8. Sussman, J. L. et al. Atomic structure of acetyicholinesterase from Torpedo cal fornica: a prototypic acetyicholine-binding protein. Science 253, 872-879 (1991).

9. Jogl, G. \& Tong, L. Crystal structure of carnitine acetyltransferase and implications for the catalytic mechanism and fatty acid transport. Cell 112, 113-122 (2003)

10. Kim, A.-R., Rylett, R. J. \& Shilton, B. H. Substrate binding and catalytic mechanism of human choline acetyltransferase. Biochemistry 45, 14621-14631 (2006).

11. Lehn, J.-M. Supramolecular chemistry-scope and perspectives molecules, supermolecules, and molecular devices (nobel lecture). Angew Chem. Int. Ed. 27, 89-112 (1988).

12. Steed, J. W. \& Atwood, J. L. Supramolecular Chemistry 2nd edn (John Wiley \& Sons, Ltd., New York, 2009).

13. Stang, P. J. Abiological self-assembly via coordination: formation of $2 \mathrm{D}$ metallacycles and $3 \mathrm{D}$ metallacages with well-defined shapes and sizes and their chemistry. J. Am. Chem. Soc. 134, 11829-11830 (2012).

14. Caulder, D. L. \& Raymond, K. N. Supermolecules by design. Acc. Chem. Res. 32, 975-982 (1999).

15. Zarra, S., Wood, D. M., Roberts, D. A. \& Nitschke, J. R. Molecular containers in complex chemical systems. Chem. Soc. Rev. 44, 419-432 (2015).

16. Fujita, M. et al. Molecular paneling via coordination. Chem. Commun. 6, 509-518 (2001).

17. Dougherty, D. A. \& Stauffer, D. A. Acetylcholine binding by a synthetic receptor: Implications for biological recognition. Science 250, 1558-1560 (1990).

18. Zhang, G. \& Mastalerz, M. Organic cage compounds from shape-persistency to function. Chem. Soc. Rev. 43, 1934-1947 (2014).

19. Kobayashi, K. \& Yamanaka, M. Self-assembled capsules based on tetrafunctionalized calix[4]resorcinarene cavitands. Chem. Soc. Rev. 44, 449-466 (2015).

20. Jordan, J. H. \& Gibb, B. C. Molecular containers assembled through the hydrophobic effect. Chem. Soc. Rev. 44, 547-585 (2015).

21. Xue, M., Yang, Y., Chi, X., Zhang, Z. \& Huang, F. Pillararenes, a new class of macrocycles for supramolecular chemistry. Acc. Chem. Res. 45, 1294-1308 (2012).

22. Guo, D.-S. \& Liu, Y. Calixarene-based supramolecular polymerization in solution. Chem. Soc. Rev. 41, 5907-5921 (2012).

23. Ahmad, N., Younus, H. A., Chughtai, A. H. \& Verpoort, F. Metal-organic molecular cages: applications of biochemical implications. Chem. Soc. Rev. $\mathbf{4 4}$ 9-25 (2015).

24. Galan, A. \& Ballester, P. Stabilization of reactive species by supramolecular encapsulation. Chem. Soc. Rev. 45, 1720-1737 (2016).

25. Wang, Z. J., Clary, K. N., Bergman, R. G., Raymond, K. N. \& Toste, F. D. A supramolecular approach to combining enzymatic and transition metal catalysis. Nat. Chem. 5, 100-103 (2013).

26. Kaphan, D. M., Levin, M. D., Bergman, R. G., Raymond, K. N. \& Toste, F. D. A supramolecular microenvironment strategy for transition metal catalysis. Science 350, 1235-1238 (2015).

27. Pluth, M. D., Bergman, R. G. \& Raymond, K. N. Acid catalysis in basic solution: a supramolecular host promotes orthoformate hydrolysis. Science 316, 85-88 (2007).

28. Inokuma, Y., Kawano, M. \& Fujita, M. Crystalline molecular flasks. Nat. Chem 3, 349-358 (2011).

29. Cullen, W., Misuraca, M. C., Hunter, C. A., Williams, N. H. \& Ward, M. D. Highly efficient catalysis of the Kemp elimination in the cavity of a cubic coordination cage. Nat. Chem. 8, 231-236 (2016).

30. Liu, Y. et al. Self-aggregating deep cavitand acts as a fluorescence displacement sensor for lysine methylation. J. Am. Chem. Soc. 138, 10746-10749 (2016).

31. Hansell, C. Cellular imaging: buckets of binding. Nat. Chem. 5, 550 (2013).

32. Ghale, G. et al. Chemosensing ensembles for monitoring biomembrane transport in real time. Angew Chem. Int. Ed. 53, 2762-2765 (2014).

33. Ciardi, M., Galán, A. \& Ballester, P. Tetra-phosphonate calix[4]pyrrole cavitands as multitopic receptors for the recognition of ion pairs. J. Am. Chem Soc. 137, 2047-2055 (2015).

34. Ghang, Y.-J. et al. Selective cavitand-mediated endocytosis of targeted imaging agents into live cells. J. Am. Chem. Soc. 135, 7090-7093 (2013).

35. Javor, S. \& Rebek, J. Activation of a water-soluble resorcinarene cavitand at the water-phosphocholine micelle interface. J. Am. Chem. Soc. 133, 17473-17478 (2011).

36. Hof, F., Trembleau, L., Ullrich, E. C. \& Rebek, J. Jr. Acetylcholine recognition by a deep, biomimetic pocket. Angew Chem. Int. Ed. 42, 3150-3153 (2003).

37. Ballester, P., Shivanyuk, A., Far, A. R. \& Rebek, J. Jr. A synthetic receptor for choline and carnitine. J. Am. Chem. Soc. 124, 14014-14016 (2002). 
38. Biros, S. M., Ullrich, E. C., Hof, F., Trembleau, L. \& Rebek, J. Jr. J. Kinetically stable complexes in water: the role of hydration and hydrophobicity. J. Am. Chem. Soc. 126, 2870-2876 (2004).

39. Kang, S. O., Begum, R. A. \& Bowman-James, K. Amide-based ligands for anion coordination. Angew Chem. Int. Ed. 45, 7882-7894 (2006).

40. Bowman-James, K., Bianchi, A. \& García-España, E. (eds) Anion Coordination Chemistry (Wiley-VCH, New York, 2012).

41. Busschaert, N., Caltagirone, C., Van Rossom, W. \& Gale, P. A. Applications of supramolecular anion recognition. Chem. Rev. 115, 8038-8155 (2015).

42. Gale, P. A. \& Quesada, R. Anion coordination and anion-templated assembly: highlights from 2002 to 2004. Coord. Chem. Rev. 250, 3219-3244 (2006).

43. Li, S. et al. A triple anion helicate assembled from a bis(biurea) ligand and phosphate ions. Angew Chem. Int. Ed. 50, 5721-5724 (2011).

44. $\mathrm{Wu}, \mathrm{B}$. et al. The effect of the spacer of bis(biurea) ligands on the structure of $\mathrm{A}_{2} \mathrm{~L}_{3}$-type ( $\mathrm{A}=$ anion) phosphate complexes. Chem. Eur. J. 21, 2588-2593 (2015).

45. Yang, D. et al. Encapsulation of halocarbons in a tetrahedral anion cage. Angew Chem. Int. Ed. 54, 8658-8661 (2015).

46. Wu, B. et al. Tetrahedral anion cage: self-assembly of a $\left(\mathrm{PO}_{4}\right)_{4} \mathrm{~L}_{4}$ complex from a tris(bisurea) ligand. Angew Chem. Int. Ed. 52, 5096-5100 (2013).

47. Jia, C., Zuo, W., Zhang, D., Yang, X.-J. \& Wu, B. Anion recognition by oligo(thio)urea-based receptors. Chem. Commun. 52, 9614-9627 (2016).

48. Jia, C. et al. Highly efficient extraction of sulfate with a tripodal hexa-urea receptor. Angew Chem. Int. Ed. 50, 486-490 (2011).

49. Zhao, J. et al. Anion coordination-induced turn-on fluorescence of an oligourea-functionalized tetraphenylethene in a wide concentration range. Angew Chem. Int. Ed. 53, 632-6636 (2014).

50. Hof, F. Host-guest chemistry that directly targets lysine methylation: synthetic host molecules as alternatives to bio-reagents. Chem. Commun. 66, 10093-10108 (2016).

51. Rizzuto, F. J., Wu, W.-Y., Ronson, T. K. \& Nitschke, J. R. Peripheral templation generates an $\mathrm{M}_{6}^{\mathrm{II}} \mathrm{L}_{4}$ guest-binding capsule. Angew Chem. Int. Ed. 55, 7958-7962 (2016).

52. Hynes, M. J. EQNMR: a computer program for the calculation of stability constants from nuclear magnetic resonance chemical shift data. J. Chem. Soc Dalton Trans. 0, 311-312 (1993).

53. Korbakov, N. et al. Acetylcholine detection at micromolar concentrations with the use of an artificial receptor-based fluorescence switch. Langmuir $\mathbf{2 4}$, 2580-2587 (2008)

54. Kuzmič, P. Program DYNAFIT for the analysis of enzyme kinetic data: application to HIV proteinase. Anal. Biochem. 237, 260-273 (1996).

55. Minaker, S. A., Daze, K. D., Ma, M. C. F. \& Hof, F. Antibody-free reading of the histone code using a simple chemical sensor array. J. Am. Chem. Soc. 134 $11674-11680$ (2012).

56. Guo, D.-S., Uzunova, V. D., Su, X., Liu, Y. \& Nau, W. M. Operational calixarene-based fluorescent sensing systems for choline and acetylcholine and their application to enzymatic reactions. Chem. Sci 2, 1722-1734 (2011).

57. Hennig, A., Bakirci, H. \& Nau, W. M. Label-free continuous enzyme assays with macrocycle-fluorescent dye complexes. Nat. Methods 4, 629-632 (2007).

58. Nau, W. M., Ghale, G., Hennig, A., Bakirci, H. \& Bailey, D. M. Substrateselective supramolecular tandem assays: monitoring enzyme inhibition of arginase and diamine oxidase by fluorescent dye displacement from calixarene and cucurbituril macrocycles. J. Am. Chem. Soc. 131, 11558-11570 (2009).

59. Koh, K. N., Araki, K., Ikeda, A., Otsuka, H. \& Shinkai, S. Reinvestigation of calixarene-based artificial-signaling acetylcholine receptors useful in neutral aqueous (water/methanol) solution. J. Am. Chem. Soc. 118, 755-758 (1996).

60. Shiraishi, Y., Miyamoto, R. \& Hirai, T. A hemicyanine-conjugated copolymer as a highly sensitive fluorescent thermometer. Langmuir 24, 4273-4279 (2008).
61. Grimme, S., Antony, J., Ehrlich, S. \& Krieg, H. A consistent and accurate ab initio parametrization of density functional dispersion correction (DFT-D) for the 94 elements H-Pu. J. Chem. Phys. 132, 154104 (2010).

62. Hostaš, J. et al. A nexus between theory and experiment: non-empirical quantum mechanical computational methodology applied to cucurbit[n] urilguest binding interactions. Chem. Eur. J. 22, 17226-17238 (2016).

63. Rai, S. K. et al. Experimental and theoretical study for the assessment of the conformational stability of polymethylene-bridged heteroaromatic dimers: a case of unprecedented folding. Cryst. Growth Des. 16, 1176-1180 (2016).

\section{Acknowledgements}

We thank Prof. Sichun Zhang and Miss Xingyu Si in Tsinghua University for help in HRMS analysis. We are grateful to the financial supports of National Natural Science Foundation of China (21271149 and 21325102), Northwest University (15NW09), and Education Department of Shaanxi (16JS113). The work by R.C. at Oak Ridge National Laboratory (X-ray structural analysis) was supported by the U.S. Department of Energy, Office of Science, Basic Energy Sciences, Chemical Sciences, Geosciences, and Biosciences Division. J.H. and P.H. acknowledge supports from research Project RVO (61388963) of the Institute of Organic Chemistry and Biochemistry Academy of Sciences of the Czech Republic; Czech Science Foundation (P208/12/G016) and project L01305 of the Ministry of Education, Youth and Sports of the Czech Republic.

\section{Author contributions}

C.J., B.W., R.G., and X.-J.Y. conceived the project; C.J., W.Z., and Y.C. carried out the experimental work. D.Y. and R.C. conducted the X-ray structural analysis. J.H. and P.H conducted the DFT calculations. L.C. and Y.-Y.W. contributed to the analysis of the twodimensional NMR data. All the authors contributed to the design of the experiments and the writing of the paper.

\section{Additional information}

Supplementary Information accompanies this paper at doi:10.1038/s41467-017-00915-8.

Competing interests: The authors declare no competing financial interests.

Reprints and permission information is available online at http://npg.nature.com/ reprintsandpermissions/

Publisher's note: Springer Nature remains neutral with regard to jurisdictional claims in published maps and institutional affiliations.

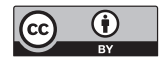

Open Access This article is licensed under a Creative Commons Attribution 4.0 International License, which permits use, sharing, adaptation, distribution and reproduction in any medium or format, as long as you give appropriate credit to the original author(s) and the source, provide a link to the Creative Commons license, and indicate if changes were made. The images or other third party material in this article are included in the article's Creative Commons license, unless indicated otherwise in a credit line to the material. If material is not included in the article's Creative Commons license and your intended use is not permitted by statutory regulation or exceeds the permitted use, you will need to obtain permission directly from the copyright holder. To view a copy of this license, visit http://creativecommons.org/ licenses/by/4.0/.

(C) The Author(s) 2017 